PAOLA CANTÙ

\title{
ARISTOTLE'S PROHIBITION RULE ON KIND- CROSSING AND THE DEFINITION OF MATHEMATICS AS A SCIENCE OF QUANTITIES
}

\author{
Abstract
}

The article evaluates the 'domain postulate' of the Classical Model of Science and the related Aristotelian prohibition rule on kind-crossing as interpretative tools in the history of the development of mathematics into a general science of quantities. Special reference is made to Proclus' Commentary to Euclid's First Book of Elements, to the sixteenth century translations of Euclid's work into Latin and to the works of Stevin, Wallis, Viète and Descartes. The prohibition rule on kind-crossing formulated by Aristotle in Posterior Analytics is used to distinguish between conceptions that share the same name but are substantively different: for example the search for a broader genus including all mathematical objects; the search for a common character of different species of mathematical objects; and the effort to treat magnitudes as numbers.

\section{INTRODUCTION}

I first faced the problem of understanding the meaning of the terms 'quantity', 'magnitude' and 'magnitude in general' in previous research on Hermann Grassmann. Criticism of the so-called traditional definition of mathematics as science of quantities abounds in the works of philosophers and mathematicians of the nineteenth century, especially in the writings of German speaking authors. Christian Wolff, who introduced a German terminology for mathematics and philosophy, used just one word ('Größe') to express both Latin words 'quantitas' and 'magnitudo', adding linguistic ambiguities to the difficulties concerning the conceptual difference between the terms. Kant, Bolzano, Hegel, and Grassmann all criticized the definition

* I would like to thank for their comments, suggestions and criticisms: Jonathan Barnes, Ivor Grattan-Guinness, and an anonymous referee. 
of mathematics as Grössenlehre and the confusion between numerical quantities and extensive magnitudes. To understand such a criticism one needs to understand when the definition became popular and what it was aimed at. It's a very difficult task, because the terms 'quantitas', 'quantity', 'quantità', 'quantité' on the one hand and 'magnitudo', 'magnitude', 'grandezza', 'grandeur' on the other hand were often used ambiguously and because the same definition was adopted by different authors to convey distinct conceptions of mathematics. Moreover the emergence of that definition was strictly connected to the development of the concept of mathesis universalis and to the preference for one or other of the words 'quantitas' and 'magnitudo' to translate the Euclidean term 'méghezos'.

In the following I will briefly illustrate some relevant elements to understand the rise of the so-called 'traditional' definition of mathematics as a 'science of quantities' or a 'science of magnitudes in general'. I will then introduce three different conceptions of mathematics as a science of quantities. Finally, I will try to investigate the relation between these three conceptions of mathematics and Aristotle's prohibition rule on kindcrossing:

you cannot prove anything by crossing from another kind - e. g. something geometrical by arithmetic. [...] where the kinds are different, as with arithmetic and geometry, you cannot attach 
arithmetical demonstrations to what is incidental to magnitudes unless magnitudes are numbers. [...] Hence the kind must be the same, if a demonstration is to cross (Post. Anal. 7, 75a35-75b10, p. 12).

I will argue that Aristotle's prohibition rule might be useful as a historical interpretative tool to bring out certain differences in meaning of the term 'quantity' as used by different authors. I will compare it to the first condition of the Classical Model given by De Jong and Betti (2008): “All propositions and all concepts (or terms) of S [Aristotelian science] concern a specific set of objects or are about a certain domain of being $(s) "$.

Among the authors that contributed to the rise of the definition of mathematics as a science of quantities from the second half of the sixteenth century to the beginning of the seventeenth century, I will cite here: first, the humanists who translated Euclid and who discussed Proclus' Commentary to the Elements and Aristotle's theory of demonstration; second, two authors that greatly contributed to the development of algebra and especially to its application to geometry: Viète and Descartes; finally, two authors that contributed to the reduction of the study of geometrical magnitudes to the study of numbers: Stevin and Wallis.

I will present three different conceptions of the domain of mathematics associated to three different strategies to explain the internal unity of mathematics: 1) the search for a broader genus including all mathematical 
objects; 2) the search for a common character of different species of mathematical objects; and 3) the effort to treat magnitudes as numbers. After giving some historical examples of each strategy, I will investigate if and how these strategies might cope with Aristotle's prescription.

\section{THE DEFINITION OF MATHEMATICS AS A 'SCIENCE OF QUANTITIES'}

In a previous work (Cantù 2003, 2) I suggested that the rise of the definition of mathematics as a 'science of quantities' was related to the spread of a philosophical conception that associated proportion theory with the general science described in Proclus' Commentary to the First Book of Euclid's Elements. According to such a conception, the domain of proportion theory is more general than the domain of arithmetic or geometry. It is constituted by 'magnitudes in general' or quantities, whose properties are expressed by the Euclidean common notions and by the definitions of Book $\mathrm{V}$ of the Elements concerning equality. I do not pretend to reconstruct here the origin of the definition of mathematics as a science of quantities - a task that would undoubtedly require longer research and the contribution of different disciplines - but I will briefly mention some elements that cannot be ignored in order to undertake such a task:

- Aristotle's remark in Posterior Analytics that some theorems on proportions can be demonstrated in a general way and the association of this observation with the idea of a general science 
made by Proclus in the aforementioned Commentary;

- the influence of Proclus' suggestion on some humanistic editions of Euclid's Elements and the preference expressed by some humanists for translating 'méghezos' into 'quantitas', arguing that the latter term is broader than 'magnitudo' and is therefore more apt to denote continuous as well as discrete quantities, namely numbers as well as geometrical magnitudes;

- the development of algebra and the application of algebraic symbols to geometrical magnitudes and to numbers, ending in an identification of quantities with numbers, considered both discontinuous and continuous as used in algebra.

\section{ARISTOTLE AND PROCLUS}

I will briefly quote two passages from Aristotle's Posterior Analytics and I will quickly summarize the idea of a general science that is to be found in Proclus' Commentary to the First Book of Euclid's Elements.

Aristotle wrote that it is sometimes possible to prove something in a science by a different science, as when we prove something in harmonics by arithmetic or in optics by geometry, but in such cases a science is somehow higher than the other.

Things of this kind are indeed proved in the same way, but there is a difference: the fact falls under one science (for the underlying kind is 
different), while the reason falls under the higher science which is concerned with the attributes which hold of it in itself (Post. Anal. 9, 76a10-15, p. 14).

Aristotle remarked that something is not proved universally and primitively, when it is proved separately for different items even though there is something higher it can be proved of, even if it lacks a name:

it might be thought that proportion alternates for items as numbers and as lines and as solids and as times. In the past this used to be proved separately, although it is possible to prove it of all cases by a single demonstration: because all these items - numbers, lengths, times, solids - do not constitute a single named item and differ in form from one another, they used to be taken separately. Now, however, it is proved universally: what they suppose to hold of them universally does not hold of them as lines or as numbers but as this (Post. Anal. 5, 74a15-25, p. 9).

In the first part of the Prologue to his Commentary on the First Book of Euclid's Elements, Proclus mentioned certain simple theorems that are common to all classes of mathematical objects and that can be observed alike in numbers, magnitudes and motions. He enumerated the theorems governing proportion, namely, the rules of compounding, dividing, converting, and alternating; the theorems concerning ratios; the theorems 
about equality and inequality in their most general and universal aspects, as having a nature common to all mathematical forms; finally he mentioned beauty, order, and the methods called analysis and synthesis (Comm. in Eucl. 7.13-8.8). Proclus did not clearly explain what he intended by a nature common to numbers, magnitudes and motions, but in a following passage in the section devoted to Postulates and Axioms Proclus unified number and magnitude under the concept of quantity. Enumerating some postulates that are common to arithmetic and geometry, he wrote that the postulate that quantity is capable of indefinite decrease is common to both, for both number and magnitude are capable of such an increase (Comm. in Eucl. 184.11-29). The general science Proclus was talking about is nonetheless not a science of quantities, for he also wrote that the general science

does not consider it its province to study the properties that belong intrinsically to numbers, nor those that are common to all quantities; rather it contemplates that single form of being or existence that belongs to all things, and for this reason it is the most inclusive of the sciences, all of which derive their principles from it (Comm. in Eucl. 9.19-25, p. 8).

\section{THE TRANSLATIONS OF EUCLID'S ELEMENTS IN THE SIXTEENTH CENTURY}

The definition of mathematics as a science of quantities was absent both in Aristotle and in Proclus: was it present in the mathematical tradition? And 
was there any hint to a general science of proportions? Euclid proved theorems on proportions in three different chapters of the Elements: the general theory for commensurable and incommensurable magnitudes developed by Eudoxus is introduced in Book V; certain applications to geometry are presented in Book VI; and a theory of proportions among numbers is contained in Book VII. Although he did not provide an explicit definition of the word, Euclid made use of the undefined word 'méghezos' in the fifth Book of the Elements, where he introduced the general theory of proportions. He never used the Aristotelian expression 'tò posòn' to denote quantity. The word 'pelikotès' occurs twice to denote ratios of homogeneous magnitudes and quantities of given ratios (Elem. V. Def. 3, VI. Def. 5*).

As Crapulli (1969) observed, different editions of the Elements provided distinct translations of the word 'méghezos'. Editions based on the Latin translation from Arabic by Campanus of Novara - such as Pacioli's Latin edition of 1509, Tartaglia's Italian edition of 1543 and Scheubel's Latin edition of 1550 - translated 'méghezos' into 'quantitas': the word 'quantitas' was associated with the Aristotelian property of being equal or unequal and was considered more general than 'magnitudo', the latter being used to denote lengths, areas or volumes. On the contrary, translations based on the Greek edition by Theon of Alexandria - such as the Latin editions by Zamberti and Commandino published respectively in 1505 and 1572 translated 'méghezos' into 'magnitudo'. Although he mainly used the word 
'magnitudo' in a general sense, Commandino sometimes used it in a stricter sense and also used the expression quantity in a broader sense, for he remarked that proportion theory is valid not only for magnitudes, but also for numbers, motions and time intervals, that is to say for continuous as well as for discrete quantities (Crapulli 1969, 18-9).

In the humanistic tradition the translation of the Euclidean concept of 'méghezos' into quantity was mainly connected with the idea of a mathesis universalis and the definition of mathematics as a science of quantities. Nonetheless a certain terminological ambiguity remained: beside authors who called mathematics 'a science of quantities', there were others who called it 'a science of magnitudes in general'. In many cases - Piccolomini and Catena for example - 'quantitas' was considered as a universal genus including all 'quanta' (Crapulli 1969, 52-3) and under the influence of Proclus' science of being it was also conceived ontologically. Moreover proportion theory was conceived - for example by Piccolomini - as a general science common to geometry and to arithmetic: this 'scientia communis' was assumed to have its own domain, its own principles and to be superordinate to geometry and arithmetic (Crapulli 1969, 39).

\section{THE DEVELOPMENT OF ALGEBRA}

Whereas the aforementioned authors sometimes conceived this general science from a philosophical rather than a strictly mathematical perspective, 
from the end of the sixteenth century onwards the idea of a general mathematical science became increasingly connected with the concept of algebraic calculus. Viète and Descartes conceived the theory of proportions as something common to geometry and arithmetic in the sense that it could be applied to both sciences, but they developed distinct applications for geometry and for arithmetic. Both used more frequently the expression 'magnitude in general' rather than the word 'quantity'.

In his work In artem analyticen Isagoge (1591) François Viète developed his Logistica speciosa, that is to say a pure, general algebra that could be applied to geometrical magnitudes and to numbers: it was both a theory of equations and a theory of proportions. Viète introduced the key concept of a species, that should be assimilated neither to the Platonic or Pythagorean conception of mathematical objects as separate entities nor to the Aristotelian conception of mathematical objects as abstract entities. According to the reconstruction of Jakob Klein, Viète's concept of species might be considered as a generalization and transformation of the Diophantine concept of 'èidos', as "the characteristic of its kind which a number shares with other numbers, or by which it is, in turn, separated from them so that a classification of numbers can be obtained" (Klein 1968, 143, 163). Comparing the role of analysis in geometry and in the Diophantine Arithmetic, Viète extended the usual calculus on numbers to a calculus on species: Ars analytica was applied to numbers and to geometrical 
magnitudes, but did not entail a fusion or a reunion of the two concepts, for algebraic procedures were common to arithmetic and to geometry, but had different applications in the two cases (Viète 1591, 137; Klein 1968, 346).

Descartes is more ambiguous than Viète, because he sometimes mentioned a general science saying that particular sciences were subordinate to it, as in the unpublished Regulae ad directionem ingenii ( $4^{\text {th }}$ Rule), where he called the general science 'universal mathematics' because it extends to all objects of the mathematical disciplines and besides to many other objects (Descartes 1701). He thus assumed that all mathematical disciplines (arithmetic, geometry but also astronomy, music, optics, mechanics and many others) were subordinated to universal mathematics, or - as he said were 'parts' of it. Descartes' conception could be described as Aristotelian, because the general science included numbers, figures, stars, sounds, but its domain was not identified with quantity - even though all mentioned items were 'quantities' in the Aristotelian sense of the word. In the fourteenth rule Descartes introduced on the contrary the concept of a 'magnitudo in genere', which seems to be the name of a genus including different species: everything that can be asserted of the genus can be asserted of the species. But what are the species of such genus? They are 'multitudines' and 'magnitudines', namely discrete and continuous entities that can be compared by order and measure. Even though he sometimes expressed himself according to the traditional terminology of genera and species, I 
don't think Descartes intended to define universal mathematics on the basis of a common ontological genus, as it seemed to be the case in Proclus' Commentary. Descartes remarked that magnitudes and numbers are distinct, though magnitudes can sometimes be reduced to numbers and numbers can be used to solve certain problems concerning measure. Universal mathematics - he wrote - can be applied to all things that can be compared according to 'multitudo' and 'magnitudo', order and measure. The domain of mathematics is actually constituted by relations, and particularly by proportions among 'magnitudes in general'. In some parts of the Regulae, Descartes also tried to relate magnitudes in general to a particular species of magnitudes, that is to say to the extension of bodies, which constitutes the object of physics. Interestingly enough, Descartes unlike Viète used figures and not just symbols to represent algebraic magnitudes (Klein 1968, 198).

Descartes' and Viète's developments of algebra did not necessarily entail the fusion of arithmetic and geometry into a common science, even though the two sciences were compared and the relation to algebraic equations stimulated the proliferation of new construction methods, the analysis of their legitimacy and new classifications of geometrical problems according to the correspondent equations to be solved (Bos 2001). Arithmetic and geometry remained distinct and numbers were not directly applied to geometry, because of their inadequacy to express irrational magnitudes, but also because of the difference in dimension: algebraic operations, when 
applied to geometry, needed a dimensional interpretation that might distinguish different classes of homogeneous figures, such as lines, planes and solids.

While Viète and Descartes used the term 'magnitude in general', in the works of Stevin and Wallis algebraic numbers were considered as the main object of mathematics and they were called 'quantities'. The differences between numbers and geometrical magnitudes were quite evident to Viète and to Descartes: they did not question the difference - inherited from the Greek tradition - between discrete a-dimensional numbers and continuous dimensional geometrical figures. On the contrary, such a difference was refuted by Simon Stevin, who already in 1585, in his book L'Arithmétique, refuted the idea that numbers were discontinuous and magnitudes continuous by criticizing the Greek conception of number as a multitude of units. He defined number as what explains the quantity of each thing. The unity is itself a number - he argued - for it is a part of any number and the part of a whole has the same nature of the whole, just as a piece of bread is bread. Moreover he remarked that the unity can be divided and that therefore numbers need not be considered discontinuous. The parts of the unity - he said - are themselves numbers, just as the parts of lines are lines: they are fractions. The relation between numbers and magnitudes was for him a correspondence: to a continuous magnitude corresponds a continuous number and if the magnitude is divided in a discontinuous way, the 
associated number is discontinuous. For this reason he concluded that discrete numbers do not stand in contrast to discontinuous magnitudes (Stevin 1585, 502).

John Wallis in his work Mathesis universalis considered universal algebra as coinciding with arithmetic, or at least as being better represented by its symbols, because "universal algebra is actually arithmetical rather than geometrical": since "geometry is almost subordinate to arithmetic" - he argued - what is universally said in arithmetic can be applied to geometry as to a subordinate science. Wallis concluded that the calculus was not geometrical but arithmetical, even though it could be applied to geometrical measures, also because geometry was limited to three dimensions, whereas the arithmetical calculus could extend to superior powers. He also remarked that the arithmetical calculus might compare squares and cubes, what would be impossible in geometry, because it would be impossible to compare inhomogeneous magnitudes such as a plane and a solid (Wallis 1657, 56). Defining a number, as Newton after him, as the ratio of two homogeneous quantities, Wallis tended to restrict the domain of universal mathematics to algebraic numbers. Number is not radically different from magnitude, because both are continuous and the former can be used to represent the latter (Wallis 1657, 133). For Wallis, mathematics can be defined as a science of quantities, where quantities should be intended not in the general sense used by Aristotle but in a restricted sense: quantities should include 
magnitudes and numbers as its only proper species; in a broader sense quantities are instead object of mixed mathematical sciences (Wallis 1657, 17).

If Viète and Descartes conceived 'magnitudes in general' as a common character of different species of objects, namely magnitudes and multitudes, Stevin and Wallis shared a different conception of mathematics. They conceived quantities as the objects of arithmetic, provided that numbers were extended to what we now call 'real numbers'. Accepting irrational numbers together with rational numbers, Stevin and Wallis could express any ratio of two quantities by a number and could therefore reduce geometry to arithmetic.

\section{THREE DISTINCT CONCEPTIONS OF QUANTITY}

I have argued that the search for a unique definition of mathematics as a science including both arithmetic and geometry should be related to the developments of the theory of proportions, whose theorems could be demonstrated - as Aristotle himself observed - not only separately for numbers and for geometrical magnitudes but also in a more general way. I have also argued that the traditional definition of mathematics as a science of quantities is connected with Aristotle's demonstration theory and with Proclus interpretation of it. I have finally presented some examples from the end of the sixteenth century to the first half of the seventeenth century that 
attest different conceptions of mathematics denoted by the same definition. I will now investigate their compatibility with Aristotle's prohibition rule on kind crossing, which I have partly used to bring out the differences themselves.

Although the definition of mathematics as a science of quantities was widely accepted and maintained until the eighteenth century, the concept of quantity varied its meaning according to different authors and at different times. The examples I have mentioned show different ways of conceiving the term quantity and the relation between particular mathematical sciences such as geometry and arithmetic and a general science of quantity. Aristotle's prohibition rule and his remarks on quantity and on scientific demonstration play a significant role in these examples, both when Aristotle's theory is accepted and when it is criticized. Apart from explicit references to the Aristotelian texts, as it is the case in the humanistic writings and in Wallis, the compatibility with the Aristotelian rule might serve to distinguish three different conceptions of algebra and three different meanings of the word 'quantity' or 'magnitude in general'.

1) The first conception is characterized by the predominance of Proclus' interpretation of the Aristotelian prohibition rule, which leads to the idea that quantity is the domain of a general mathematical science whose content includes magnitudes, numbers, sounds, and motions and whose 
theorems concern proportions and equalities or inequalities. I would attribute this conception to many humanistic texts of the sixteenth century, but perhaps also to certain texts of Descartes, such as the passage taken from the $4^{\text {th }}$ Rule of Regulae. The Aristotelian prohibition rule on kind-crossing is respected inasmuch as quantity is intended as a superior genus including numbers and geometrical magnitudes: geometry and arithmetic are subordinate to a general science of quantity. This point of view needs not however correspond to the Aristotelian conception for it seems to be based on an ontological perspective influenced by Proclus' Platonism: there is a higher genus and it has a name, whereas Aristotle seems to conceive this genus not as a domain of being but as a common character of different species whose higher genus has no name.

2) The second conception might be characterized by the restriction of the concept of quantity (or magnitude in general) to figures and numbers, namely to geometrical and arithmetical objects, following Euclid rather than Aristotle or his commentators. Such a restriction is not based on the genusspecies distinction: the word quantity does not refer to a genus including numbers and geometrical magnitudes, but it denotes a new symbolic concept whose properties could be derived from the properties of the operations on algebraic symbols. The prohibition rule seems nonetheless to be somehow maintained, at least in the loose sense that neither Viète nor Descartes ever consider the idea of applying algebraic procedures to numbers and to 
geometrical magnitudes in exactly the same way: they rather develop different procedures for each science. Viète and Descartes take into serious account the intrinsic differences between numbers and geometrical magnitudes, such as continuity and dimension. That's why, for example, they insist on the necessity of introducing homogeneity conditions in proportion theory when it applies to magnitudes. The difference between arithmetic and geometry is thus maintained as essential and relevant: the tendency to prove something geometrical by arithmetic is not yet spread, though the means for doing it are developed.

3) The third conception might be connected to further developments of the algebraic calculus. The development of algebra does not induce the identification of arithmetic and geometry, but tends to subordinate the latter to the former, inasmuch as arithmetic is conceived as a general algebra. The attention is drawn to problems concerning the possibility of demonstrating geometrical results by algebraic expressions, that is to say - at least according to Wallis' understanding of algebra - by arithmetical expressions. For Stevin the continuity of geometrical magnitudes is adequately expressed by their numbers, that inherit the continuity of the things they are numbers of. Neither continuity nor dimensionality are exclusive features of geometrical magnitudes anymore. The prohibition rule does not seem to be relevant and Aristotle's broad conception of quantity is criticized. Quantities are magnitudes and numbers, or simply numbers, in as far as numbers can 
represent the ratios of any two magnitudes and arithmetic can compare quantities of different dimensions, namely polynomials of different degree.

\section{ARISTOTLE'S PROHIBITION RULE ON KIND-CROSSING AND THE CLASSICAL MODEL OF SCIENCE}

By the aforementioned analysis of the three different conceptions of mathematics as a science of quantities I have tried to show that Aristotle's prohibition rule on kind crossing might be quite useful from a historical point of view, especially in order to individuate relevant differences among conceptions that share the same name. Firstly, analyzing whether quantity is intended as a superordinate genus including numbers, magnitudes and many other entities, or just numbers and magnitudes, or as a domain of entities of different species whose superior genus lacks a name, one discovers interesting differences in the concept of quantity. Secondly, Aristotle's prohibition rule on kind crossing might explain certain resistances to the idea of unifying numbers and magnitudes in a single genus or to the idea of applying the algebraic calculus in exactly the same way to arithmetic and to geometry. Thirdly, Aristotle's remarks on a general science besides special sciences such as arithmetic and geometry might help in understanding how the idea of a mathesis universalis merged with the algebraic conception of arithmetic. Moreover, the prohibition rule, together with Aristotle's considerations on mathematical entities, might explain why proportion theory could not be so easily considered as a special science: propositions on 
proportions do not concern some genus in an ontological sense but rather different items such as numbers, lengths, times, and solids. Finally, the prohibition rule helps to understand the difference between those authors who refuted the idea of reducing geometry to arithmetic and those who tended to identify algebra with arithmetic.

The first condition of the Classical Model, which De Jong and Betti call 'domain postulate', is strictly connected to the prohibition rule on kindcrossing and to the hierarchical disposition of sciences. This postulate is satisfied whenever the internal unity of a science is provided by its subjectmatter, intended as a specific set of objects or a certain domain of beings. The domain postulate, as far as mathematics is concerned, does not assume that the domain of objects should be as broad as possible, that is that it should contain all entities that share the properties demonstrated in the theorems: I think it lacks an essential strive for generalization that was embedded in Aristotle's demonstration theory. Aristotle's formulation is a useful guideline, because it helps to understand the development of proportion theory into a mathesis universalis. To have an equivalent of such a strive for generalization, a specific reference to the Aristotelian conception of genus and species should perhaps be included in the first condition of the model.

Even though the first condition of the Classical Model is very helpful in 
the construction of a general interpretative frame, the frame might result too comprehensive when applied to historical case-studies, letting interesting distinctions vanish. The views of Wallis, Viète and Descartes would all be compatible with the first condition of the Classical Model, since the concepts of universal arithmetic, logistica speciosa and universal algebra might be grounded on the idea of a domain consisting of a specific set of objects; but this would result, in my view, in understating some essential differences among such definitions of mathematics. A specific reference to the doctrine of genus and species might be useful to understand the relation between the Classical Model and Aristotle's epistemology, and to provide the historian with a tool that points out not only common traits but also substantive differences.

\section{References}

Aristotle, Analytica Posteriora. (Engl. transl. by J. Barnes (1994) Posterior Analytics. Oxford: Clarendon Press.)

Bos, H. (2001) Redefining Geometrical Exactness. Descartes' Transformation of the Early Modern Concept of Construction. (New York: Springer)

Cantù, P. (2003) La matematica da scienza delle grandezze a teoria delle forme. L'Ausdehnungslehre di H. Graßmann [Mathematics from Science of Quantities to Theory of Forms. H. Grassmann's Ausdehnungslehre], Dissertation. Genova: Università degli Studi di Genova

Cantù, P. (2008) Mathematik als Größenlehre. In: Stolzenberg, J. and Rudolph O.-P. (eds) 
Christian Wolff und die europäische Aufklärung. Akten des 1. Internationalen WolffKongresses, Halle (Saale), 4.-8.April 2004. (Hildesheim; Zürich; New York: Olms) (in press)

Crapulli, G. (1969) Mathesis universalis. Genesi di un'idea nel XVI secolo. [Mathesis universalis. The genesis of an idea in the $16^{\text {th }}$ century] (Roma: Edizioni dell'Ateneo)

De Jong, W.R. and Betti, A. (this issue) The Aristotelian Model of Science: A Millennia-Old Model of Scientific Rationality.

Descartes, R. (1701) Regulae ad directionem ingenii. In Opuscula postuma, physica et mathematica, (Amsterdam: Blaeu). (Repr. in G. Crapulli (Ed.) (1966) La Haye: Nijhoff.)

Euclid, Elementa. In: J. L. Heiberg (1883-88) (Ed.) (Leipzig. Teubner). (Engl. transl. by Thomas L. Heath (1956) The thirteen books of Euclid's Elements. Dover: New York)

Klein, J. (1968) Greek Mathematical Thought and the Origin of Algebra. (Cambridge, Mass.: M.I.T. Press)

Proclus, Commentarium in primum Euclidis Elementorum librum. In G. Friedlein (Ed.) (1873) (Leipzig: Teubner). (Engl. transl. by G. R. Morrow (1970), A Commentary on the First Book of Euclid's Elements. Princeton, NJ: Princeton University Press)

Stevin, S. (1585). L’Arithmétique. (Leyde: Plantin). (Repr. in E. J. Dijksterhuis et al. (Eds.) (1958), The Principal Works of Simon Stevin, vol. II. Mathematics, (pp. 488-507). Amsterdam: Swets and Zeitlinger.)

Viète, F. (1591) In artem analyticen Isagoge (Tours: Mettayer). (Repr. in Francisci Vietæ Opera mathematica, recognita Franscisci a SCHOOTEN. Leyde: Elzevier, 1646). (Repr. Hildesheim-Zürich-New York: Olms, 1970).

Wallis, J. (1657). Mathesis universalis (Oxford: Robinson). (Repr. in Opera, vol. I, Oxford: 
Theatro Sheldoniano,1695.) (Repr. Hildesheim; New York: Olms, 1972) 